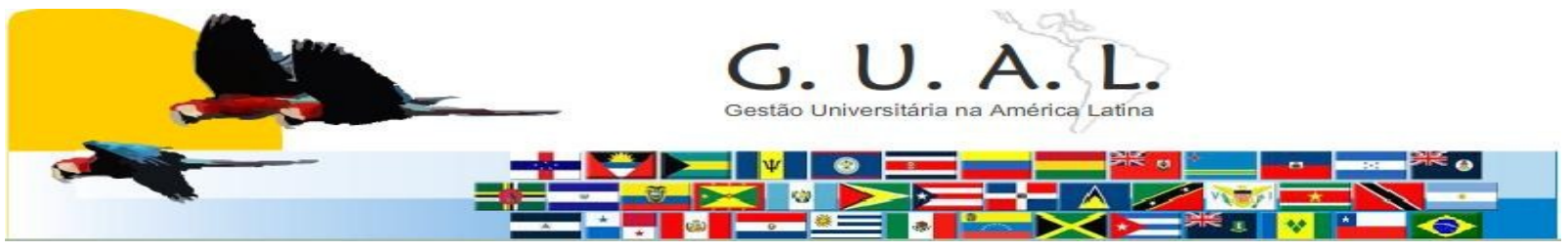

ISSN 1983-4535

\title{
SISTEMA DE INFORMAÇÃO GERENCIAL OBSERVATÓRIO DA EDUCAÇÃO
}

Oscar Dalfovo, FURB

Lucimar Lídia Depiné Dalfovo, FURB

\begin{abstract}
RESUMO
A competitividade de um mundo globalizado e em constante mudança exige que as instituições de ensino superior estejam sempre atentas e em busca da qualidade e satisfação de seus alunos. Estes itens são decisivos para assegurar a continuidade das instituições mais tradicionais, uma vez que novas faculdades e cursos surgem a cada ano, e também para garantir que estas novas instituições tornem-se competitivas e mantenham-se no mercado. Para fiscalizar a qualidade e ajudar os alunos na sua escolha, o Ministério da Educação MEC e a Coordenação de Aperfeiçoamento de Pessoal de Nível Superior - CAPES avaliam a atuação dos cursos de graduação e pós-graduação ofertados pelas instituições de ensino superior. O Programa de Pós-Graduação em Administração - PPGAd da Fundação Universidade Regional de Blumenau - FURB, o qual é recomendado pela CAPES desde 2000, também está em busca de qualidade e satisfação dos seus alunos. Para auxiliá-lo nesta tarefa, este trabalho apresenta o protótipo do Sistema de Informação Gerencial Observatório da Educação. Este sistema, o qual foi desenhado a partir do mapa estratégico do PPGAd da FURB, permite aos usuários visualizar informações relevantes para a tomada de decisão estratégica. Para o desenvolvimento deste trabalho foi utilizada a pesquisa exploratória com abordagem qualitativa.
\end{abstract}

Palavras-chaves: sistemas de informação. sistema de informação gerencial. balanced scorecard. mapa estratégico. instituições de ensino superior

Rev. GUAL., Florianópolis, v.2, n. 1, p.62-77, ano 2009. 


\section{INTRODUÇÃO}

Este trabalho consiste na proposta do Sistema de Informação Gerencial Observatório da Educação, o qual tem por objetivo permitir que o Programa de Pós Graduação em Administração - PPGAd da Fundação Universidade Regional de Blumenau - FURB visualize informações em nível gerencial. Este sistema permite a administração das informações, auxiliando na tomada de decisão estratégica, a qual pode proporcionar o crescimento da instituição, melhora da qualidade de ensino e aumento da satisfação dos alunos.

Para atender o objetivo do trabalho, inicialmente foi realizado um estudo sobre Sistemas de Informação - SI e Sistema de Informação Gerencial - SIG. Prosseguiu-se com a análise dos indicadores de desempenho, com enfoque no modelo Balanced Scorecard - BSC e no mapa estratégico. Em seguida, o foco do estudo foram as Instituições de Ensino Superior - IES, mais especificamente a FURB e o PPGAd. O próximo passo foi a pesquisa sobre o Observatório da Educação e a apresentação da relação entre SIG e IES. Com estes estudos e a análise dos documentos fornecidos pela Coordenação de Aperfeiçoamento de Pessoal de Nível Superior - CAPES, foram identificados os indicadores de desempenho estratégicos para a organização. Com os indicadores definidos, foi delineado o mapa estratégico para o PPGAd. Em seguida, com base neste mapa, foi desenhado o Sistema de Informação Gerencial Observatório da Educação.

\section{SISTEMAS DE INFORMAÇÃO}

Conforme Stair e Reynolds (2002) e Dalfovo (2004), Sistemas de Informação - SI são conjuntos de elementos ou componentes inter-relacionados que coletam (entrada), manipulam e armazenam (processo), disseminam (saída) os dados e informações e fornecem um mecanismo de feedback. A entrada é a atividade de captar e reunir novos dados. O processamento envolve a conversão ou transformação dos dados em saídas úteis. A saída envolve a produção de informação útil. O feedback é a saída usada para fazer ajustes ou modificações nas atividades de entrada ou processamento.

\subsection{Tipos de sistemas de informação}

Laudon e Laudon (2004) apresentam os seis tipos mais importantes de SI correspondentes a cada nível organizacional. A organização tem sistemas de apoio ao 
executivo (SAEs) no nível estratégico; sistemas de informação gerencial (SIGs) e sistemas de apoio à decisão (SADs) no nível gerencial; sistemas de trabalhadores do conhecimento (STCs) e sistemas de automação de escritórios no nível do conhecimento e sistemas de processamento de transações (SPTs) no nível operacional.

\subsection{Sistema de informação gerencial}

Oliveira, (2002, p. 40) define SIG como "o processo de transformação de dados em informações que são utilizadas na estrutura decisória da empresa, proporcionando, ainda, a sustentação administrativa para otimizar os resultados esperados”.

Nash e Roberts (1984-5 apud OLIVEIRA, D., 2002, p. 40) conceituam SIG como uma combinação de pessoas, facilidades, tecnologias, ambientes, procedimentos e controles, com os quais se pretende manter os canais essenciais de comunicação, processar certas rotinas típicas de transações, alertar os executivos para a significância dos eventos internos e externos e proporcionar uma base para a tomada de decisão inteligente.

Laudon e Laudon (2004, p.44) afirmam que o termo sistemas de informações gerenciais (SIGs) designa uma categoria específica de SI que dão suporte às funções do nível gerencial, munindo os gerentes de relatórios, ou de acesso on-line aos registros do desempenho corrente e histórico da organização. Normalmente são orientados quase que exclusivamente aos eventos internos, e não aos eventos ambientais ou externos. Apóiam, primordialmente, as funções de planejamento, controle e decisão no nível gerencial. Geralmente dependem dos sistemas de processamento de transações subjacentes para a aquisição de dados.

Os SIGs usualmente atendem aos gerentes interessados em resultados semanais, mensais e anuais e não em atividades diárias. Eles em geral dão respostas a perguntas rotineiras que foram especificadas anteriormente e cujo procedimento de obtenção de respostas é predefinido. Esses sistemas geralmente não são flexíveis e sua capacidade analítica é reduzida. A maior parte dos SIGs usa rotinas simples, como resumos e comparações, em vez de sofisticados modelos matemáticos ou técnicas estatísticas.

De acordo com Lapolli (2003), o principal objetivo de um SIG é disponibilizar informações para a tomada de decisões, ou seja, sistemas tipicamente fornecedores de relatórios. O usuário solicita por meio de menus, uso de comandos, a informação que necessita. Com base na solicitação do usuário, o SIG pesquisa em sua base de dados e fornece 
a informação apresentando-a da melhor maneira possível. Os meios de apresentação da informação podem ser os mais variados possíveis: textual (relatórios descritivos), planilhas ou gráficos. O nível de detalhe da informação disponibilizada deverá ser adequado às necessidades de cada usuário.

O mesmo autor afirma que a utilização de um sistema de informações gerenciais visa principalmente tornar as organizações mais ágeis. Fornecer informação que possibilite visualizar a real situação da organização dentro do mercado em que está inserida. Permitir o planejamento de novas estratégias de ação. Identificar os pontos fortes e fracos da organização. Armazenar informações sobre a concorrência e sobre as necessidades dos consumidores.

\section{OBSERVATÓRIO DA EDUCAÇÃO}

O Observatório da Educação é uma parceria da Coordenação de Aperfeiçoamento de Pessoal de Nível Sperior (CAPES/MEC) e do Instituto Nacional de Estudos e Pesquisas Educacionais (Inep/MEC). O objetivo do programa é "incrementar o desenvolvimento de pesquisas em educação, para estimular a produção acadêmica e ampliar o pensamento crítico em relação às políticas públicas.” (NERY, 2007)

No artigo $2^{\circ}$ do decreto $n^{\circ} 5.803$, de 8 de junho de 2006, o presidente da república Luiz Inácio Lula da Silva dispõe sobre o Observatório da Educação. A iniciativa foi lançada em 2006 e apóia projetos de pesquisa voltados à educação em pelo menos um dos temas: educação básica, educação superior, educação profissional, educação continuada e educação especial, confome Brasil (2006).

As organizações precisam adquirir a capacidade de explorar os seus ativos intangíveis, precisam de uma modelo de desempenho que esteja de acordo com sua missão e visão e precisam de uma ferramenta que lhes permita visualizar informações relevantes para a decisão estratégica.

Desta forma, um SIG, o qual é um método organizado para prover aos administradores de informações precisas e atualizadas, é uma opção interessante para as instituições de ensino visualizarem seus indicadores. 


\section{MÉTODO DE PESQUISA}

Para o desenvolvimento deste trabalho foi utilizada a pesquisa exploratória com abordagem qualitativa. De acordo com Oliveira, S. (2002), a pesquisa qualitativa tem como objetivo situações complexas ou estritamente particulares. Ela possui a facilidade de poder descrever a complexidade de uma determinada hipótese ou problema, analisar a interação de certas variáveis, compreender e classificar processos dinâmicos experimentados por grupos sociais, apresentar contribuições no processo de mudança, criação ou formação de opiniões de determinado grupo e permitir, em maior grau de profundidade, a interpretação das particularidades dos comportamentos ou atitudes dos indivíduos. Tem como objetivo a formulação de um problema para efeito de uma pesquisa mais precisa ou, ainda, para a elaboração de hipóteses.

Inicialmente, foi realizado estudo sobre SI, SIG, IES, Indicadores de Desempenho e BSC. A seguir, foi feito o levantamento dos indicadores de desempenho. Após esta etapa, elaborou-se o mapa estratégico para o PPGAd. Em seguida, foi desenhado o Sistema de Informação Gerencial Observatório da Educação com base neste mapa. A população foi composta pelos professores do PPGAd, considerando senso.

Foram realizadas entrevistas com professores do Programa de Pós-Graduação em Administração - PPGAd, com a finalidade de entender seus objetivos e indicadores. Em outra etapa, foram analisados dois documentos da CAPES: Critérios de Avaliação Trienal. Triênio avaliado: 2004 - 2007. Área de avaliação: Administração/Turismo. Ficha de Avaliação do Programa. Período de avaliação: 2004 a 2006. Etapa: Avaliação Trienal 2007. IES: Administração. Modalidade: Acadêmico.

Com base nestes documentos e nos estudos realizados, desenhou-se o mapa estratégico do PPGAd. Em seguida, foi desenvolvido o protótipo do Sistema de Informação Gerencial Observatório da Educação.

\section{RESULTADO DA PESQUISA}

Com base nos objetivos propostos por este trabalho e nas informações contidas em documentos fornecidos pela CAPES, foi desenvolvido o mapa estretégico do PPGAd e o protótipo de um Sistema de Informação Gerencial, os quais são apresentados neste capitulo. O

Rev. GUAL., Florianópolis, v.2, n. 1, p.62-77, ano 2009. 
sistema permite ao usuário visualizar a avaliação do mestrado de Administração. Utiliza como base os dados cadastrados previamente por um sistema de processamento de transações.

Foram seguidas três fases de desenvolvimento e a implementação de um SIG: fase de conceituação do SIG, fase do levantamento e da análise do SIG e fase de estruturação do SIG. Por tratar-se de um protótipo, a fase de implementação e avaliação do SIG não foi contemplada.

\subsection{SIG Observatório da Educação}

No menu do sistema apresenta-se Participação por item, Avaliação Geral, Avaliação das Questões e junto ao menu está o mapa estratégico. Ao clicar no link Avaliação dos Quesitos, são mostrados novos links para o usuário. Caso o usuário clique em algum quesito, o sistema mostra as opções disponíveis para o quesito escolhido, de acordo com a Figura 1.

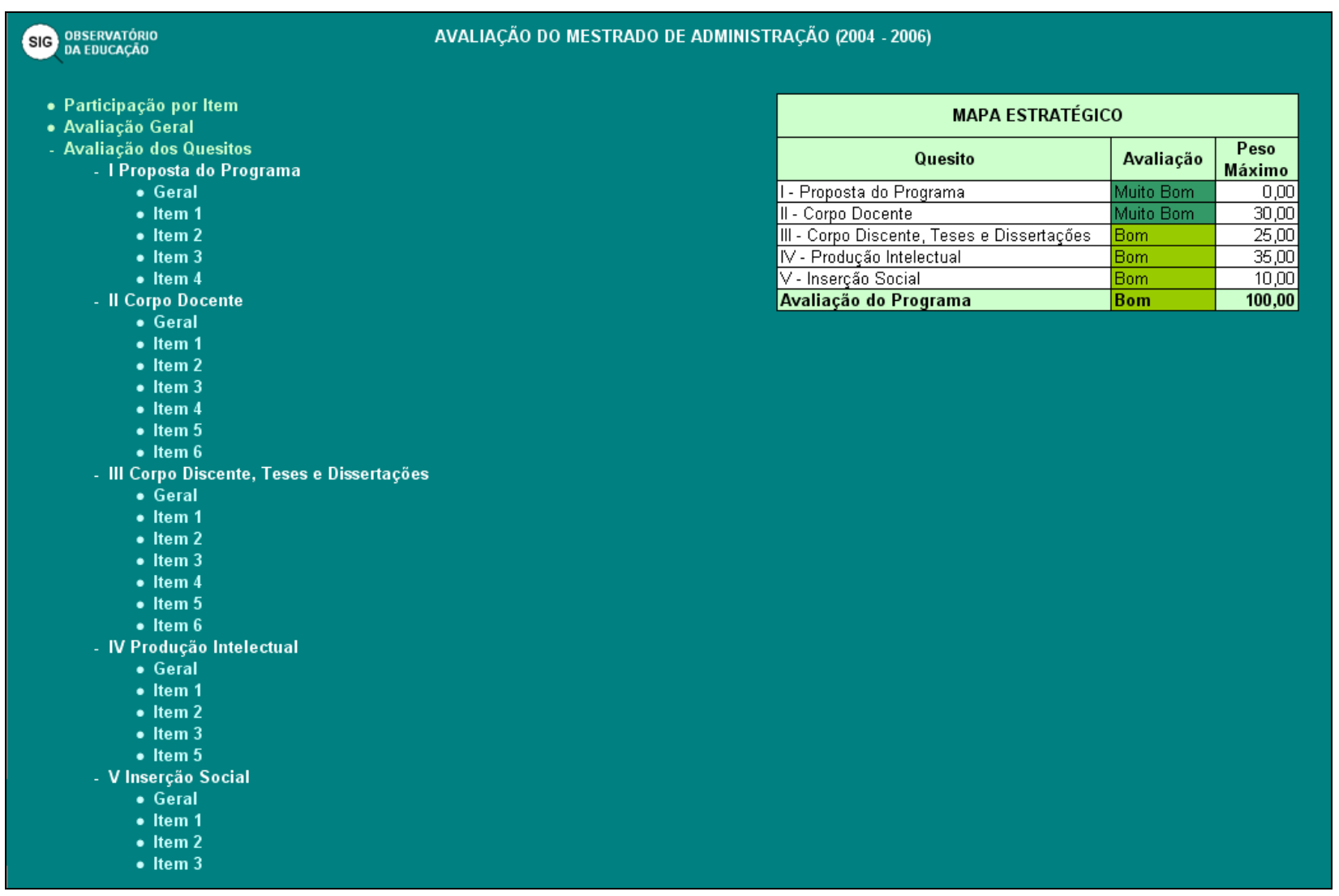

Figura 1 - Menu do sistema detalhado por itens

O primeiro item do menu apresenta a participação de cada item dentro do seu quesito, ou seja, mostra qual é a importância deste item para o quesito, conforme pode ser 
visto na Figura 2. O quesito I não é apresentado, pois a CAPES não atribui pesos para os seus itens.

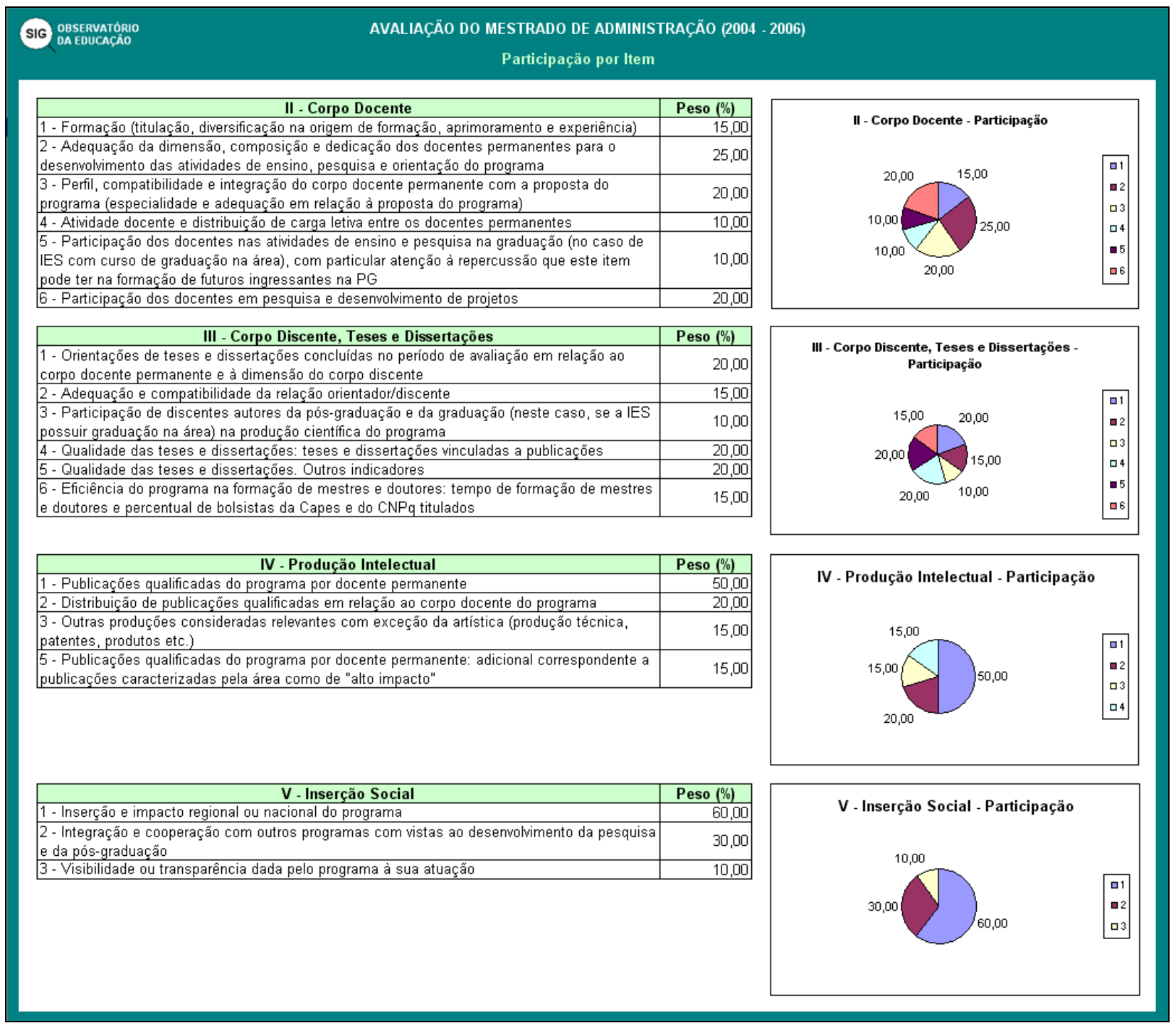

Figura 2 - Participação por item

\subsubsection{Quesito I - Proposta do programa}

Ao escolher a opção Geral do Quesito I - Proposta do Programa, o sistema mostra a avaliação de todos os itens pertencentes a este quesito. O quesito I não tem atribuição de peso, ou seja, a avaliação não é quantitativa, e sim qualitativa. Desta forma, apenas um conceito é apresentado na tela. A CAPES apresenta cinco conceitos para avaliar um quesito ou item. Optou-se por diferenciá-los por cores no sistema para facilitar a visualização e o entendimento. Os conceitos são muito bom (verde escuro), bom (verde claro), regular 
(amarelo), fraco (laranja claro) e deficiente (laranja escuro). Ainda há a opção de não aplicável, a qual é apresentada na cor branca.

$\mathrm{Na}$ tela de comparação, o usuário pode voltar para a tela anterior clicando no link do canto inferior direito. No menu principal, ao clicar no Item 1 do Quesito I, o sistema mostra a avaliação deste item. Este item refere-se à coerencia, consistência, abrangência e atualização das áreas de concentração, linhas de pesquisa e projetos em andamento (pesquisa, desenvolvimento e extensão). O Item 2 do Quesito I diz respeito à coerência, consistência e abrangência da estrutura curricular. Já o Item 3 do Quesito I é sobre a infra-estrutura para ensino, pesquisa e extensão. $\mathrm{Na}$ avaliação do Item 4 do Quesito I, o qual refere-se às atividades inovadoras e diferenciadas de formação de docentes.

\subsubsection{Quesito II - Corpo docente}

Ao clicar no link Geral do Quesito II - Corpo Docente, o sistema apresenta a avaliação de todos os itens pertencentes a este quesito, conforme pode ser visto na Figura 3.

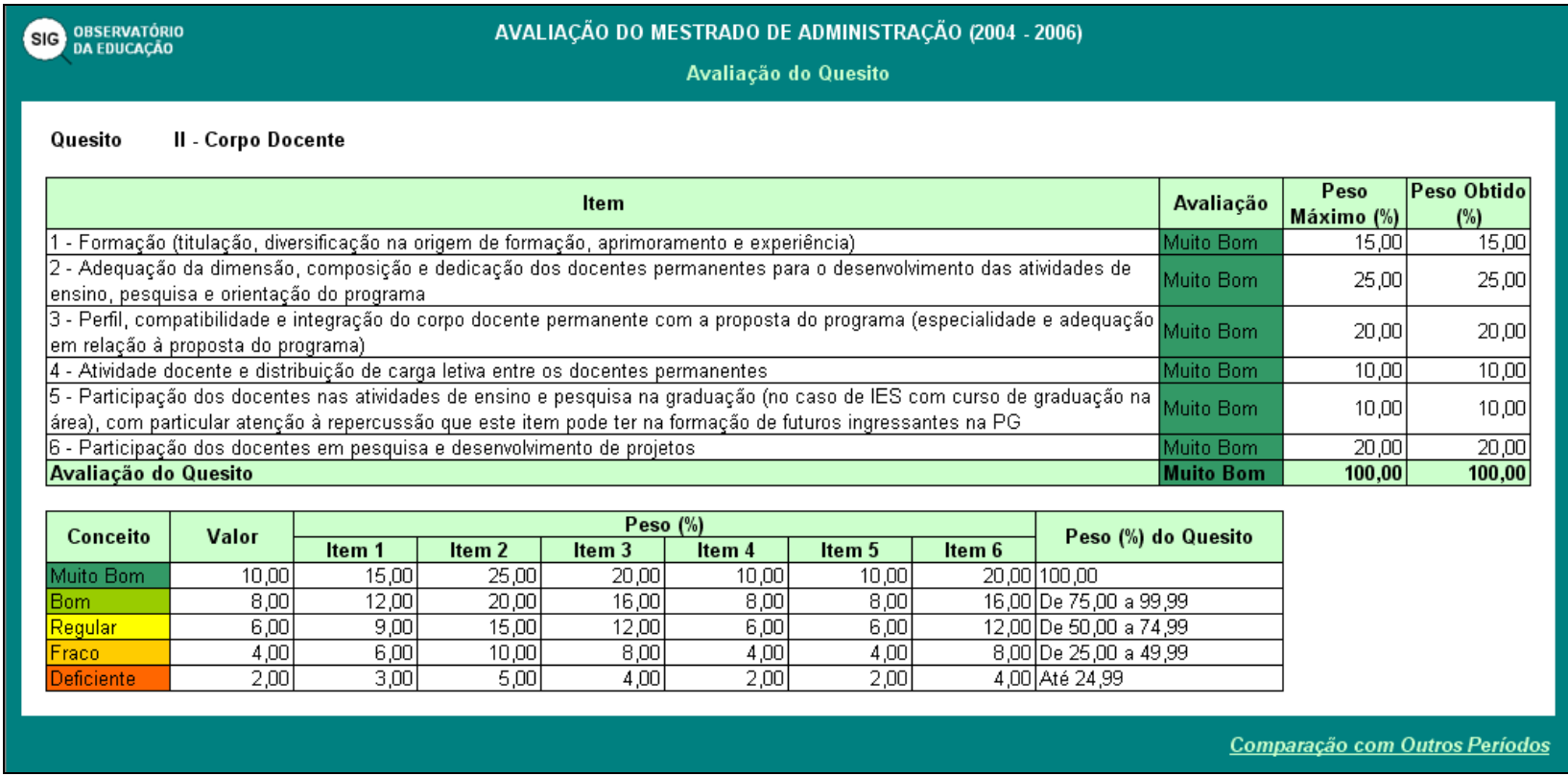

Figura 3 - Avaliação do quesito II

A CAPES fornece na sua ficha de avaliação apenas os conceitos relativos aos itens (muito bom, bom, regular, fraco e deficiente) e o peso máximo de cada item, mas ela não apresenta os pesos obtidos. Desta forma, ao desenvolver o sistema, foi estabelecida uma relação dos conceitos, pesos e valores. Para cada conceito, atribui-se um valor. Para os itens

Rev. GUAL., Florianópolis, v.2, n. 1, p.62-77, ano 2009. 
que têm cinco conceitos, como no exemplo anterior, os valores definidos. Com base nestes valores e nos pesos máximos (conceito muito bom), foi utilizada a regra de três para descobrir os pesos relativos aos demais conceitos (bom, regular, fraco e deficiente). A soma dos pesos obtidos nos itens define a avaliação do quesito. Para atribuir um conceito ao quesito, também foi feita uma relação de pesos e conceitos. O sistema também permite que o usuário visualize comparações com outros períodos. Para isto, deve-se clicar no link do fim da tela. É apresentada uma tela de acordo com a Figura 4, a qual contém um tabela com os pesos obtidos em cada período. Estes pesos servem de base para os gráficos de Evolução e Comparação. O eixo Y representa o peso obtido na avaliação, sendo que o último valor apresentado é o valor máximo possível para o item. $\mathrm{O}$ eixo $\mathrm{X}$ representa cada período avaliado.
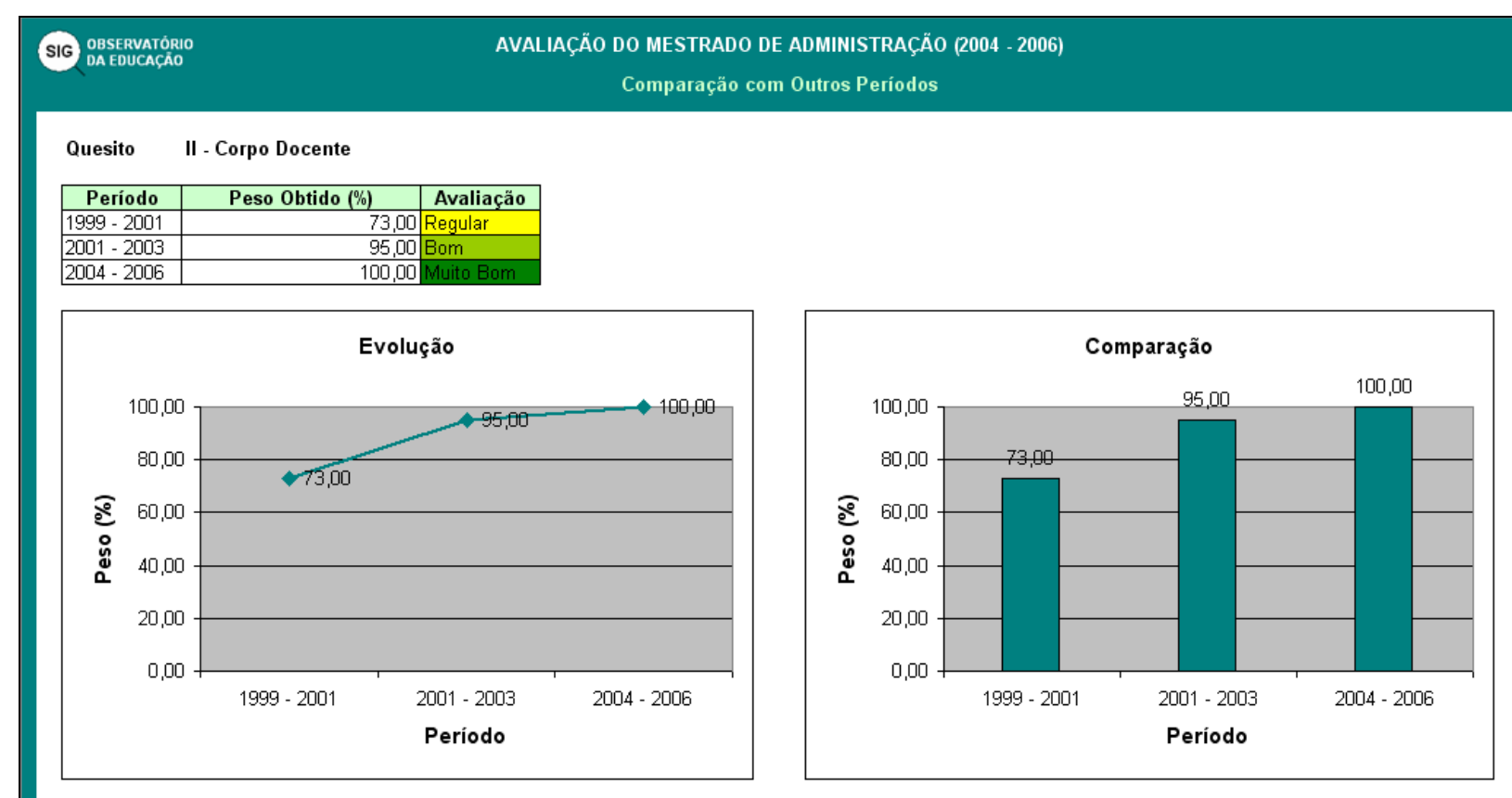

Avaliaçäo do Quesito

Figura 4 - Avaliação do quesito II - Comparação com outros períodos

No menu principal, ao clicar no Item 1 do Quesito II, o sistema mostra a avaliação deste item. Este item diz respeito à formação (titulação, diversificação na origem de formação, aprimoramento e experiência). Nas telas de avaliação de itens, o usuário também tem a opção de visualizar a comparação com períodos anteriores, conforme mostrado na Figura 5. 


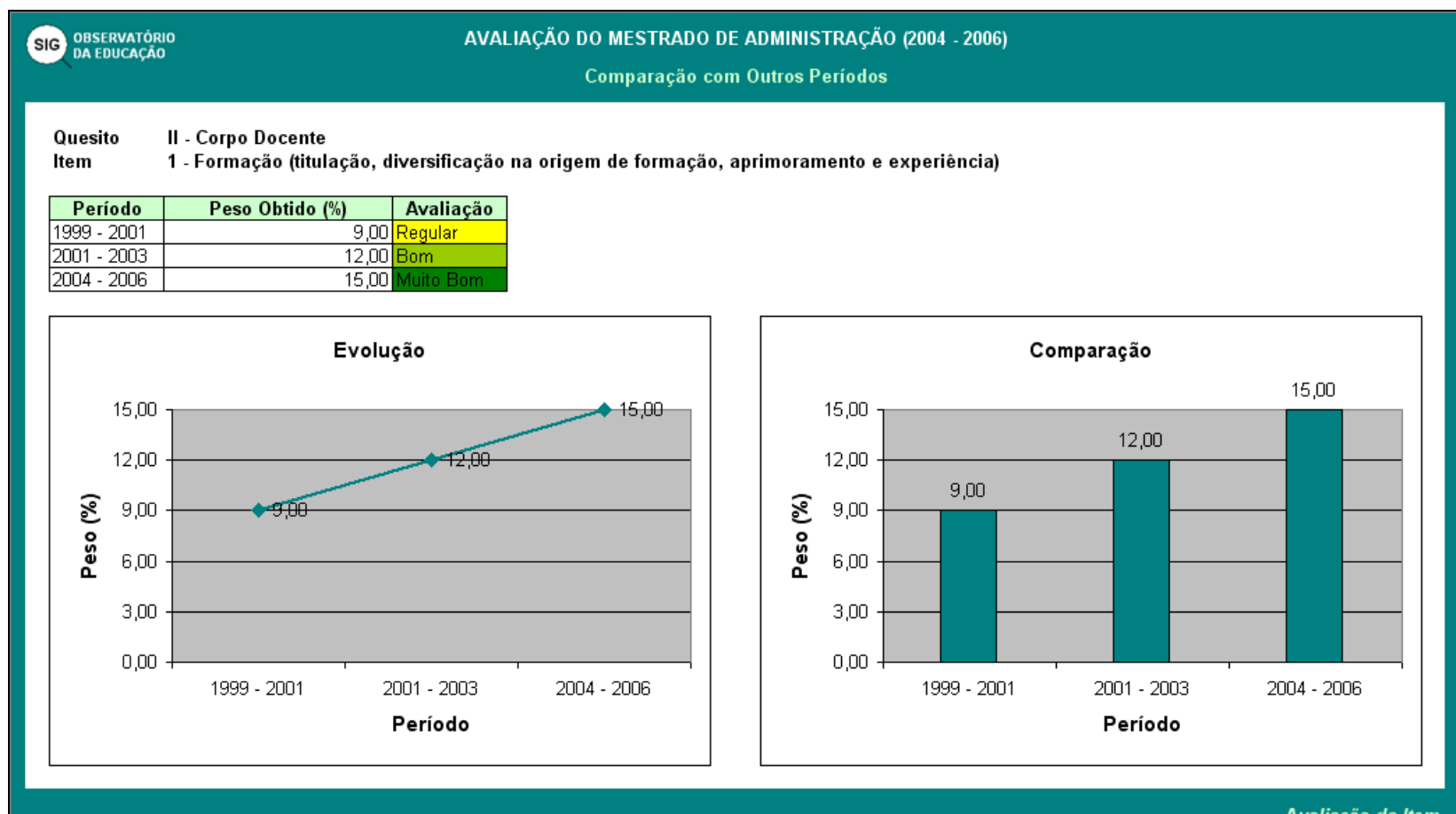

Figura 5 - Avaliação do item 1 do quesito II - Comparação com outros períodos

O item 2 do Quesito II refere-se à adequação da dimensão, composição e dedicação dos docentes permanentes para o desenvolvimento das atividades de ensino, pesquisa e orientação do programa. A avaliação do item 3, o qual diz respeiro ao perfil, compatibilidade e integração do corpo docente permanente com a proposta do programa (especialidade e adequação em relação à proposta do programa). Também é possível visualizar a avaliação do item 4, o qual refere-se à atividade docente e distribuição de carga letiva entre os docentes permanentes.

O item 5 refere-se à participação dos docentes nas atividades de ensino e pesquisa na graduação (no caso de IES com curso de graduação na área), com particular atenção à repercusão que este item pode ter na formação de futuros ingressantes na PG. O item 6, o qual diz respeito à participação dos docentes em pesquisa e desenvolvimento de projetos.

\subsubsection{Quesito III - Corpo discente, teses e dissertações}

Ao escolher a opção Geral do Quesito III - Corpo Discente, Teses e Dissertações, o sistema mostra a avaliação de todos os itens deste quesito, conforme pode ser visto na Figura 6. 
Quesito

III - Corpo Discente, Teses e Dissertaçöes

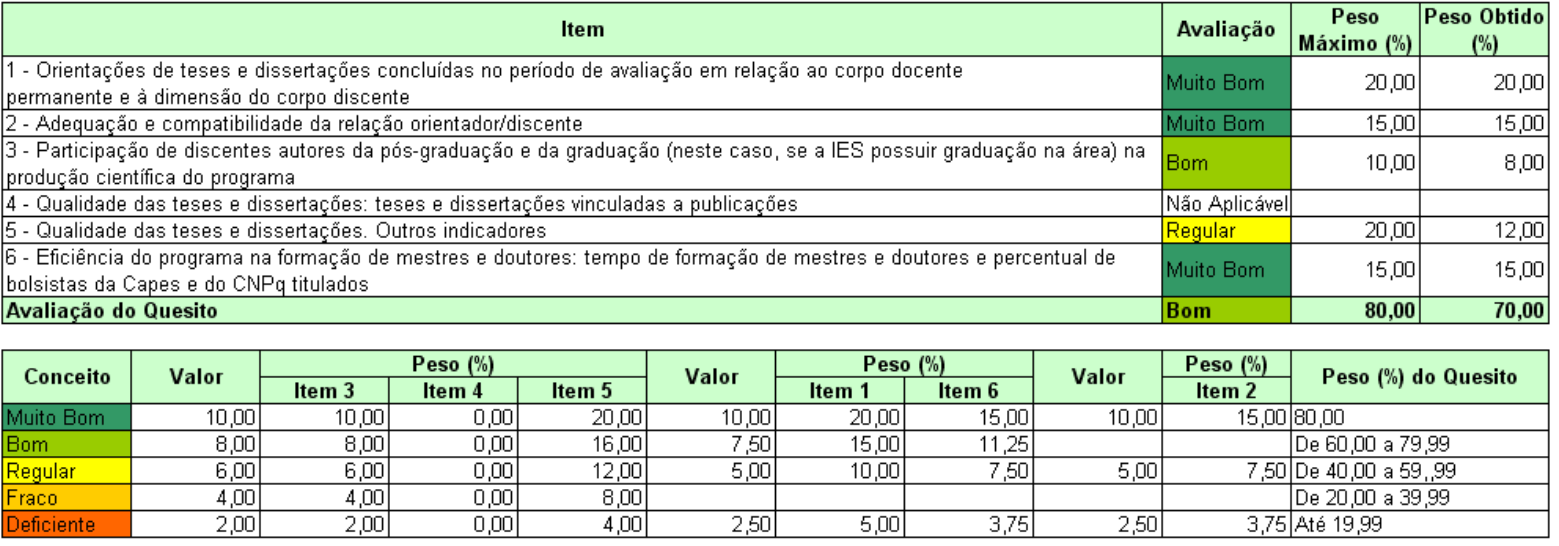

Figura 6 - Avaliação do quesito III

Conforme a Figura 6, os itens deste quesito apresentam opções diferenciadas de conceitos. Os itens 3,4 e 5 podem ser avaliados como muito bom, bom, regular, fraco e deficiente. Para estes itens seguiu-se a mesma atribuição de valores do quesito II. No entanto, os itens 1 e 6 têm apenas quatro opções de avaliação, as quais receberam os pesos.

Com base nestes valores e nos pesos máximos (conceito muito bom), a exemplo do que foi feito no quesito II, também foi utilizada a regra de três para definir os pesos relativos aos demais conceitos (bom, regular, fraco e deficiente). A soma dos pesos obtidos nos itens define a avaliação do quesito. Para atribuir um conceito ao quesito, foi feita uma relação de pesos e conceitos. O quesito III apresenta uma particularidade: a CAPES define que o item 4 $($ peso $=20,00)$ não se aplica. Desta forma, o peso máximo corresponde a 80,00. A seguir está a relação dos conceitos e pesos.

No menu principal, ao clicar no Item 1 do Quesito III, é apresentada a avaliação deste item que trata das orientações de teses e dissertações concluídas no período de avaliação em relação ao corpo docente permanente e à dimensão do corpo discente. $\mathrm{O}$ item 2 deste quesito, refere-se à adequação e compatibilidade da relação orientador/discente. $\mathrm{O}$ item 3, o qual diz respeito à participação de discentes autores da pós-graduação e da graduação (neste caso, se a IES possuir graduação na área) na produção científica do programa. Já o item 4 trata da qualidade das teses e dissertações: teses e dissertações vinculadas a publicações. O item 5 do quesito III, o qual refere-se à qualidade das teses e dissertações. Outros indicadores. 
No item 6, o qual trata da eficiência do programa na formação de mestres e doutores: tempo de formação de mestres e doutores e percentual de bolsistas da CAPES e do CNPq titulados.

\subsubsection{Quesito IV - Produção intelectual}

Ao escolher a opção Geral do Quesito IV - Produção Intelectual, o usuário visualiza a avaliação de todos os itens pertencentes a este quesito, conforme pode ser visto na Figura 7.

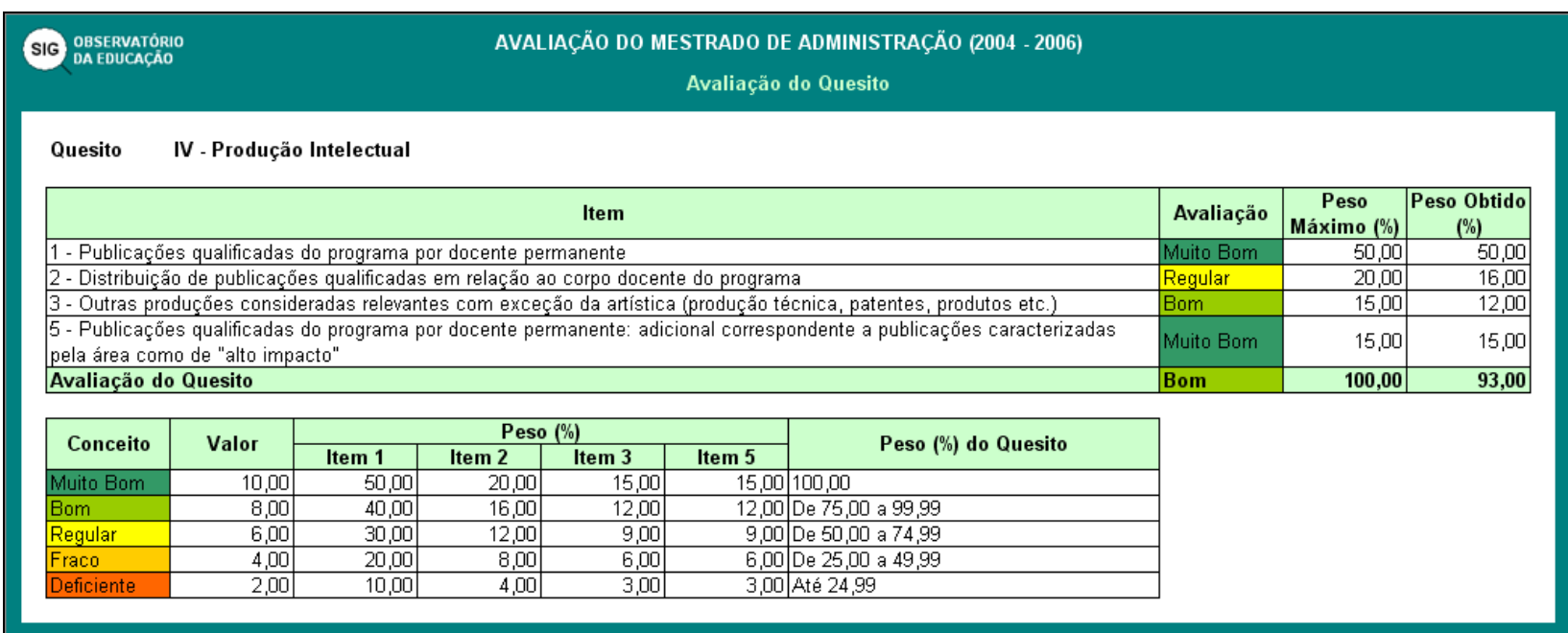

Figura 7 - Avaliação do quesito IV

Ao clicar no Item 1 do Quesito IV, é apresentada a avaliação deste item. Refere-se às publicações qualificadas do programa por docente permanente. $\mathrm{O}$ item 2 diz respeito à distribuição de publicações qualificadas em relação ao corpo docente do programa. O item 3 do quesito 4, o qual trata de outras produções consideradas relevantes com exceção da artística (produção técnica, patentes, produtos etc.). $\mathrm{O}$ item 5, o qual refere-se às publicações qualificadas do programa por docente permanente: adicional correspondente a publicações caracterizadas pela área como de "alto impacto".

\subsubsection{Quesito V - Inserção social}

No menu, ao clicar no link Geral do Quesito V - Inserção Social, o sistema apresenta a avaliação de todos os itens pertencentes a este quesito, conforme pode ser visto na Figura 8. 


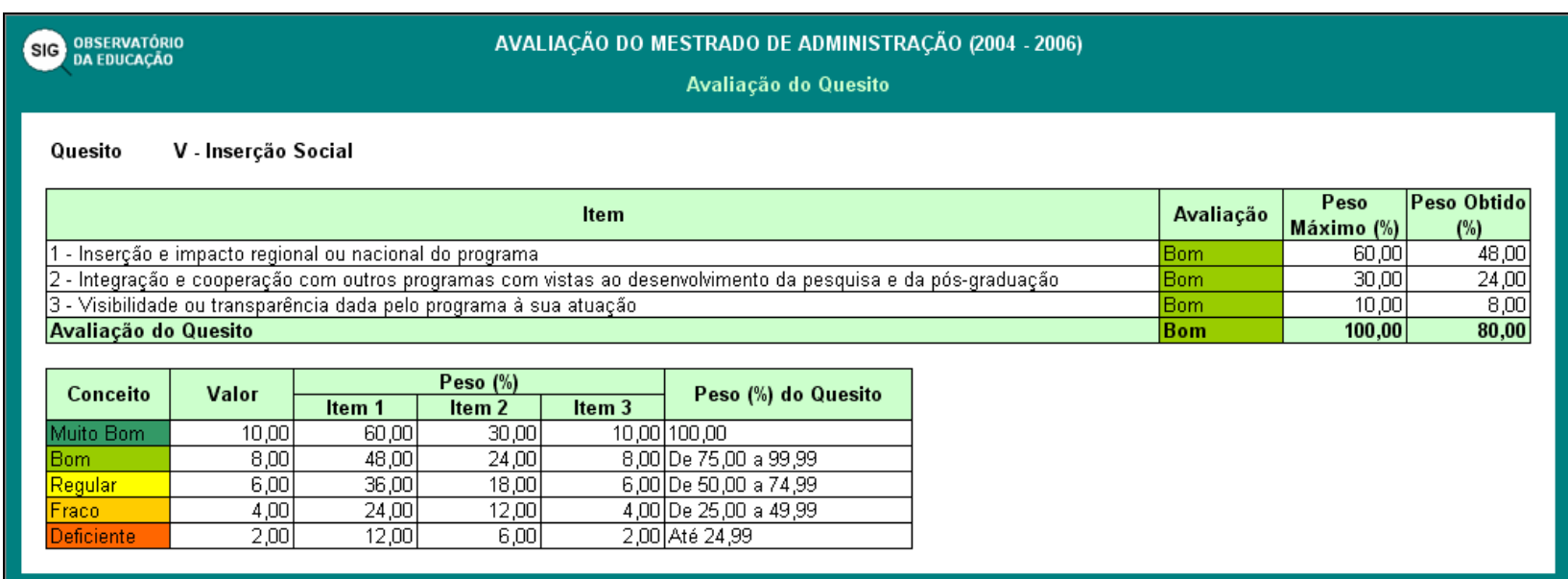

Figura 8 - Avaliação do quesito $\mathrm{V}$

O item 1 deste quesito, o qual diz respeito à inserção e impacto regional ou nacional do programa. O item 2, o qual representa a integração e cooperação com outros programas com vistas ao desenvolvimento da pesquisa e da pós-graduação. $\mathrm{O}$ item 3 , o qual refere-se à visibilidade ou transparência dada pelo programa à sua atuação.

\section{CONCLUSÕES E RECOMENDAÇÕES}

As organizações de todos os tipos necessitam de informações que permitam uma visão ampla de seus negócios, de forma a auxiliá-las no processo decisório, para garantir a sua sobrevivência em um ambiente competitivo e sujeito a mudanças constantes. Um SIG é uma maneira organizada de prover as organizações deste tipo de informação, uma vez que possibilita a visualização da situação real desta organização no mercado no qual está inserida. Desta forma, permite que os gerentes e executivos planejem suas estratégias de ação, com base na identificação de qualidades e defeitos.

A utilização de indicadores de desempenho também pode contribuir para a tomada de decisão de uma organização. Indicadores organizados e estruturados por área permitem ao gerente ter uma visão abrangente do cenário. O BSC proposto por Kaplan e Norton é um modelo que defende a idéia de que uma empresa deve ter indicadores distribuídos em quatro perspectivas: financeira, do cliente, de processos internos e de aprendizado e crescimento. Estes indicadores podem ser representados graficamente através de um mapa estratégico, o qual mostra como estão integrados e combinados para definir a estratégia da organização. 
Assim como em outras áreas, a educação também necessita estar atenta ao mercado e em busca da qualidade. Uma instituição precisa conhecer seus diferenciais e deficiências, para atender a expectativa de seus alunos e dos órgãos avaliadores. Neste sentido, a CAPES lançou o projeto Observatório da Educação, o qual é uma iniciativa que tem como objetivo incentivar o desenvolvimento de estudos e pesquisas em pós-graduação em nível stricto sensu.

O projeto SIOE da IES pesquisada é um dos núcleos do Observatório da Educação. Seu eixo temático é a educação superior e a linha de pesquisa é a de indicadores de desempenho dos sistemas de ensino.

O presente trabalho, o qual está relacionado ao projeto SIOE, teve seus objetivos atendidos. Com o estudo dos indicadores de desempenho do PPGAd da IES, os quais foram levantados a partir de documentos de avaliação da CAPES, foi possível delinear o mapa estratégico. A partir do mapa, foi elaborado o protótipo do SIG Observatório da Educação, o qual está dividido em módulos de acordo com os quesitos determinados pela CAPES.

A utilização do sistema pode trazer benefícios para o PPGAd da IES, pois a análise dos indicadores mostra a situação do programa de pós-graduação, o que pode auxiliar a instituição na identificação de pontos fortes e fracos. O sistema também apresenta gráficos que possibilitam comparar o triênio atual com os anteriores, fato que permite verificar onde houve progressos e declínios. Esta identificação pode ajudar o PPGAd a planejar suas ações para elevar o conceito do curso.

Conclui-se com este trabalho que a experiência obtida foi enriquecedora para sua autora. Seus objetivos de aprendizagem foram alcançados, pois o desenvolvimento do trabalho permitiu o estudo aprofundado de conceitos e técnicas aprendidos durante o curso de pós-graduação em Tecnologia da Informação na Gestão Integrada de Negócios. A correlação do trabalho com o projeto Observatório da Educação permitiu uma maior aproximação ao meio acadêmico.

Como sugestão de extensão deste trabalho pode-se desenvolver o SIG Observatório da Educação, ou seja, efetuar a modelagem de dados e a implementação do software. Outra sugestão é analisar e incluir indicadores qualitativos ao sistema proposto, como por exemplo, indicadores que avaliem a satisfação dos alunos, levando em consideração suas críticas e sugestões. 


\section{REFERÊNCIAS}

BRASIL. Presidência da República. Casa Civil. Subchefia para Assuntos Jurídicos. Decreto $\mathrm{n}^{\circ} 5.803$, de 8 de junho de 2006. Dispõe sobre o Observatório da Educação e dá outras providências. Disponível em:

$<$ http://www.planalto.gov.br/ccivil_03/_Ato2004-2006/2006/Decreto/D5803.htm>. Acesso em 20 out. 2007.

CAMPOS, José Antônio. Cenário balanceado: painel de indicadores para a gestão estratégica dos negócios. São Paulo: Aquariana, 1998.

DALFOVO, Oscar. Sistemas de Informação Observatório da Educação. Disponível em: $<$ http://campeche.inf.furb.br/sioe/>. Acesso em 15 ago. 2007

FURB. Fundação Universidade Regional de Blumenau. 2004. Disponível em $<$ http://www.furb.br/>. Acesso em 20 jul. 2007.

KAPLAN, Robert S.; NORTON, David P. Mapas estratégicos: convertendo ativos intangíveis em resultados tangíveis. Rio de Janeiro: Campus, 2004.

LAPOLLI, Paulo César. Implantação de sistemas de informações gerenciais em ambientes educacionais. Florianópolis, 2003. Disponível em:

$<$ http://teses.eps.ufsc.br/defesa/pdf/6060.pdf >. Acesso em: 10 jul. 2007.

LAUDON, Kenneth C.; LAUDON, Jane Price. Sistemas de informação gerenciais:

administrando a empresa digital. São Paulo: Prentice Hall, 2004.

NERY, Flavia. Observatório da Educação incentiva pesquisas em gestão e avaliação escolar. MEC. Ministério da Educação. 2007. Disponível em:

$<$ http://portal.mec.gov.br/index.php?option $=$ com content\&task $=$ view\&id $=8642>$. Acesso em: 20 out. 2007.

OLIVEIRA, Djalma de Pinho Rebolças de. Sistemas de informações gerenciais. São Paulo: Atlas, 2002.

OLIVEIRA, Silvio Luiz. Tratado de metodologia científica: projetos de pesquisas, TCI, TCC, monografias, dissertações e teses. São Paulo: Pioneira, 2002.

REZENDE, Denis Alcides. Planejamento de sistemas de informação e informática: guia prático para planejar a tecnologia da informação integrada ao planejamento estratégico das organizações. São Paulo: Atlas, 2003.

REZENDE, José Francisco de Carvalho. Balanced Scorecard e a gestão do capital intelectual: alcançando a mensuração equilibrada na economia do conhecimento. Rio de Janeiro: Campus, 2003. 
STAIR, Ralph M.; REYNOLDS, George W. Princípios de sistemas de informação. Rio de Janeiro: LTC, 2002. 